\title{
A CONCEPTUALIZATION OF KNOWLEDGE MANAGEMENT STRATEGY TOWARD ORGANIZATION PERFORMANCE IN THE LIBYAN TRANSPORTATION INDUSTRY
}

\author{
Ahmad Mohamad Omar Omran', \\ S. M. Ferdous Azam \\ Postgraduate Centre (PGC), \\ Management and Science University, \\ University Drive, Off Persiaran Olahraga, \\ 40100 Shah Alam, Selangor, \\ Malaysia
}

\begin{abstract}
:
This conceptual paper aims to examine the relationship between the knowledge management strategy and organizational performance in Libya transportation industry. Libya's government policy proposals for public organisation reform have largely failed to encourage the development of information. The transport industry is suffering from a shortage of backward-integrated equipment. Most Arab nations have inherited their transparent authoritative practises from their previous founder legacies. This is despite the way in which the region needs knowledge management as never before due to the evolving way of global aggression. Also, the introduction and use of different information technologies in an enterprise will be the key to conducting knowledge management activities in the transport industry. The promotion of trust among members of intra- and inter-organizational teams is of primary concern for the establishment of a strong and sound knowledge base. It takes some time to establish a desired knowledge culture for the sharing of knowledge and exchange of knowledge. However, only a small section of the public would appreciate gains and any aspect of it could be overlooked by the rest. It should strive to develop the academic resources of the general public and involve people in basic leadership in general.
\end{abstract}

JEL: L10; L25; L91

Keywords: knowledge management strategy, organizational performance, transportation industry, Libya

i Correspondence: email a omran1977@yahoo.com 


\section{Introduction}

In the transportation industry, the knowledge management is considered as the essential tool to bring reforms by governments for the societal improvements. It has been repeatedly noted that the "government policy initiatives for the reform of public organization have largely failed to promote knowledge creation." It is almost impossible to avoid the central importance of technology in any aspect of life. The modern era is known for the technological advancements when the organizational efficiency and the success of the employees in an organization lie in leveraging the intellectual capital that includes brands, patents, copyrights, customers and the culture within the company. The governments of developing countries including Libya need to appreciate that the adequate execution of knowledge management can help them to achieve their goals. The knowledge management affects the capability of the organizations in a manner that the integration of knowledge in the employees' performance (Azam and Moha Asri, 2015; Tham et al., 2017; Udriyah et al., 2019). In order to integrate knowledge in any organizational structure (public or private), the sources of sharing the knowledge are of central value.

The management and the organizational knowledge have to be integrated into the process and procedures of the organization for increased growth and performance. The knowledge is the key driver for development in all organizations and nations and is a keen differentiator for growth and competitiveness. The knowledge is reflected in the practice and thus, the organization knowledge remains the crucial aspect of organizational efficiency. The companies have to enable organizational culture and organizational structure within the organization to explore knowledge management. The knowledge management is vital for knowledge integration in organizations to sustain their competitive advantages (Rachmawati et al., 2019; Azam and Yusoff, 2020; Azam et al., 2020).

The knowledge management in organizations integrates knowledge with distinctive capability to improve employee performance (Azam et al., 2014; Haur et al., 2017; Katukurunda et al., 2019). This study will provide the correlation between the knowledge management (KM) strategies and the organizational performance by evaluating the factors affecting $\mathrm{KM}$ in the context of Libya. The use of information technology cannot be ignored for the purpose of this study because this is particularly critical in sharing and management of knowledge.

The Libya transportation industry is up against a competitive disadvantage when it comes to knowledge management. Transportation industry suffers from a lack in backward-integrated facilities. Knowledge Management Process is turning out to be progressively basic for different reasons. In the transportation industry, the knowledge management is considered as the essential tool to bring reforms by governments for the societal improvements. However, it has been repeatedly noted that the "government policy initiatives for the reform of public organization have largely failed to promote knowledge creation" in Libya. Only a few researches on the transportation industry in Libya have been 
identified. Absence of a comprehensive knowledge in this regard hinders the effort of the organizational performance in Libya transportation industry.

\section{Literature Review}

There is no uniformity or common conformity on the part of the scholars as to the definition and nature of knowledge, an intrinsically ambiguous or equivocal term. In 360 BC, in his Theaetetus, Plato defines knowledge as 'justified true belief' although debated and modified in many ways; Plato's concept of knowledge is still widely articulated in Western thought. From the above, knowledge can be understood from two perspectives: first, it is viewed as beliefs, norms, information flowing from experiences, or the capacity to act effectively.

Polanyi (1966) mentioned there were two types of knowledge - tacit and explicit. Tacit knowledge is difficult to document, categorize and share. Explicit knowledge, in contrast, is objective in nature and can be communicable in formal, systematic language. This knowledge can be expressed in words and numbers and shared in the form of data, scientific formula, specifications, manuals and the like. Knowledge generated from data related to a firm's market share, market opportunities and economic projections is critical to its growth potential, according to Baumard and Kuehn (1987). Knowledge can be viewed as a cognitive structure, the product of accumulated learning and unlearning. According to Lewin (1951), learning occurs when there is a gap between the current state of knowledge and some desired state. The more an individual learns, the more s/he unlearns. Organizational knowledge is drawn from different organizational knowledge sources. These include knowledge held by individuals as well as embedded in the strategies, processes, procedures, and rituals maintained by the organization.

\subsection{Dimensions of Knowledge Management Strategies}

In general, from two viewpoints, the literature sheds light on the dimensions of KM strategies: one, the hard aspects, i.e. technological, and the other, the soft problems, i.e. social (Mason and Pauleen, 2003; Dewi et al., 2019; Nguyen et al., 2019). The 'hard' factor holds the view that the introduction and use of different information technologies in an enterprise will be the key to conducting knowledge management activities (Mason and Pauleen, 2003). It is anchored on the premise that KM projects in the enterprise will be driven by large volumes of knowledge processed across multiple information technologies, such as data mining, data warehousing, groupware, etc. (Malhotra, 2020; Tiwana, 2020; Turban and Aronson, 2001). The 'soft' approach of KM strategies, contrary to this 'strong' view, conveys the prevalence of social relationships in an enterprise in such a way that employees cultivate a feeling for each other through the exchange of information and the maintenance of knowledge management drives (Maghfuriyah et al., 2019; De Silva et al., 2017; Kuruwitaarachchi et al., 2019; Pambreni et al., 2019; Gupta and Govindarajan, 2020). According to Lee and Choi (2003), these social dimensions include those that are found to be instrumental in their success, such as the community, structure 
and individuals employed in the organisation. Over time, as these principles and tools are incorporated into the corporate work-setting, these social aspects become impossible for others to emulate as the organisation learns and garners company excellence (Gold et al., 2001).

\subsection{Trust}

The prevalence of an environment rooted in confidence, regarded as a prime antecedent to the development of knowledge (Lee and Choi, 2003; Chun et al., 2019; Yang et al., 2019), opens the door to considerable and fruitful exchange of knowledge (Lin, 2016). This is due to the fact that team members then become less hesitant or afraid of communicating closely with each other, setting off a loop through the SECI (Socialization, Externalization, Combination and Internalization) mechanism for information formation (Takeuchi and Nonaka, 2004). In this regard, however, Robbins (2018) is raising a cautionary flag urging circumspection on the part of the leadership so that they remain mindful of the fact that confidence can be very brittle with telling consequences if not properly nurtured. The lack of confidence among employees in the way of successful transfer of information or, according to Jarvenpaa and Staples (2020), drives them to accumulate their knowledge. Therefore, the promotion of trust among members of intra- and inter-organizational teams is of primary concern for the establishment of a strong and sound knowledge base (Lubit, 2001) and is found to be positively linked to each other (Politis, 2003). Lopez et al. (2004) also stressed that a culture of organisation rooted in trust and security is an imperative for promoting new product trials and developments by exchanging and generating new ideas and information.

\subsection{Learning}

Organizational learning refers to the capacity it offers individuals in organisations to innovate and apply their expertise (Sinkula, 1994). Echoing the same, Tracy et al. (1995) named the primary qualities of learning constant creativity on their part as well as encouragement obtained from their peers and supervisors. It is an important aspect of knowledge management strategies, as it provides a company with opportunities to allow new knowledge to be enriched by its people (Nonaka and Takeuchi, 1995). Via their active involvement, the focus on learning and ongoing growth of people in an organisation results in a greater scale of information production activities (Lee and Choi, 2003). According to them, organisations need to cater to the flourishing of a profoundly rooted learning ethos and have training and education systems in place to promote learning in order for adequate knowledge growth to take place. This is because a vibrant culture of learning serves as a springboard for knowledge generation and exchange (Murray and Donegan, 2003), and encourages both formal and informal means of communication (Bhatt, 2020). Apart from this, it is of particular importance for organisations to exercise a certain degree of tolerance for errors and to treat them as a conduit for problem solving and a way forward (van Zolingen et al., 2001). 
A learning culture committed to developing people's skills and abilities helps an organisation expand its knowledge base, according to Bhatt (2020). Such learning skills make it easier for staff to apply their conceptual expertise (Tsai and Lee, 2016). This is important because it will contribute to the company developing and retaining core competencies (Simonin, 1997), where a culture of learning is found to be a precedent in activities of information formation that consequently affect organisational efficiency.

\subsection{Performance Rewards}

Organizations that respect their workers both for what they know and for exchange; and that knowledge nurtures an atmosphere that leads to efforts to manage knowledge (Zack et al., 2019). However, because the position of a knowledge worker can occupy a new role within an organisation, it takes some time to establish a desired knowledge culture for the sharing and use of knowledge. In order to promote an information sharing activity in such a community to take firm root in an organisation, it is important that the exchange of knowledge and ideas within and through teams is rewarded, not the individual success that could give way to the accumulation of knowledge (Walczak, 2015). This is in line with the enterprise, the teams that harbour an information group approach to solving problems need to be rewarded and appreciated.

\subsection{Knowledge Management in the Transportation Industry}

The key drivers for KM's late receipt in the general division of society were outlined. To begin with, adequacy of openly beneficial conveyance has been one of the long-term goals that legislatures around the world have been seeking to achieve. The choice of KM activities would promote the exchange and sharing of learning among staff. Second, updating, developing or redesigning the existing collections of knowledge or creating new ones makes the current learning accessible and safe within the association's limits. Third, the possibility of their prosperity and achievement of the fantasised outcomes will be improved based on knowledge to illuminate decisions and methods, and the basic leadership mechanism would be transparent and sound. Fourth, improved reactivity and participation in partnerships with the general population division would eventually prompt both higher cash income for people and better transmission of services.

Furthermore, KM operations should strive to strengthen the scholarly limits of the general public and build up "violent learning" work capacity. It will ensure that open learning and human capital assets are utilised and that they are better used for the general benefits of society. Essentially, convincing open agreements to the extent of collaboration and participation of open partners. All the while, the more participatory the general culture is, the more happiness it results in. It is important, however, to think about the varieties in the levels of instruction and knowledge of arrangement issues from the general population side. Since, something else, through their participation in the arrangement making process, only a small section of the general population would appreciate gains and any aspect of it could be overlooked by the rest. Consequently, to allow a rational and clear exchange of unsaid information between them, it is important 
for the legislature to create channels of communication and debate with the general public. Exchange is one of the strongest ways to engaging with people, because it is difficult for them to communicate their characteristics and assumptions in a roundabout manner, and this guarantees importance when forming arrangements. In the general population division, $\mathrm{KM}$ is, as needed, a device that upgrades hierarchical execution, as well as a medium that communicates people's desires in general and their concerns and empowers them to engage in the process of strategy making. Both these elements contribute to the general welfare of society and to the simplicity of the service apparatus at the end of the day.

A fact that is difficult to ignore is the lack of examination on KM in the Arab open part. For the most part, this is attributed to: significant quantities of lack of education, average R\&D interests and inadequate ICT. This will make the Arab world remain further behind whatever is left of the world in its attempt to move to a learning economy, on the off chance that this situation continues and non-stop as it seems to be. There is an increasing selection of KM writing, but more from a western point of view. Most Arab nations have inherited their transparent authoritative practises from their previous founder legacies and face real challenges in keeping the service apparatus viable and achieving the desired outcomes and outcomes. Little research has been carried out on the components that hinder the success of KM activities in the Arab district despite the way in which the region needs KM right now as never before due to the evolving way of global aggression and the movement to a "learning economy" or "knowledge society" where $\mathrm{R} \& \mathrm{D}$ is the main prerequisites.

Obaisat (2015) analysed the effect of organisational culture on the development of knowledge and found that faith, popular culture, visions, language and shared storeys, leadership practises and cultural norms are key to the creation of knowledge. AlShammari (2015) examined problems with the use of a data warehouse and a customer relationship management system to collect and exchange information in a Bahraini telecommunications business and found that the organisational culture was one of the factors that contributed to the failure of this initiative.

Cultural factors influencing knowledge management programmes were analysed by Holowetzki (2020) and found that these factors included information structures, organisational structure, incentive systems, procedures, people and leadership. Al-Alawi et al. (2017) identified essential success factors for Bahrain's organisational culture and knowledge sharing, where he chose trust as organisational variables, contact between employees, information system, incentive systems and organisational structure.

\section{Theoretical Review}

There are a number of theories put forward, upon which the theoretical framework is premised; these are: Technology Acceptance Model (TAM) and Resource-based View (RBV) of the Firm. The rationales of employing these theories are put forward. All these are discussed below. 


\subsection{Technology Acceptance Model (TAM)}

The Technology Acceptance Model (TAM) proposed by Davis (1989) is one of the most commonly discussed structures often used to describe the behaviour of computer usage and technology acceptance-related constructs. The model, rooted in the Principle of Rational Action (TRA) (Fishbein and Azjen, 1975), asserts that the adoption of technology is first affected by the attitudes of a consumer towards it and then defined by its intention to use, which then generates behaviours. Davis illustrates that the difference in these attitudinal and behavioural variables depends on the expectations of the individual, perceived utility (the degree to which a person believes that using a particular system improves his / her productivity) and perceived ease of use (the degree to which a person believes that using a particular system is effortless). Thus, Davis argues that 'the relationship of belief-attitude-intention-behavior predicts and explains the acceptance of consumer IT' (Huang, 2018, p. 406).

In Internet-related technology adoption studies, such as online shopping (Ahn et al., 2004), online banking (Sundarraj and Wu, 2015), e-commerce (Wang et al., 2016), egovernment (Lai and Pires, 2017), etc., the TAM model finds a broad range of applications Buonanno et al. (2015) conducted a study evaluating how large and small and mediumsized enterprises (SMEs) perceive ERP adoption in their organisations in Malaysia. Harrison and Waite (2015) explore the growth of e-commerce on the basis of a qualitative study by identifying the eleven factors that influence the use of websites among intermediaries in an extended supply chain. The analysis conducted by Tung (2018) explores the impact of the adoption by nurses of the e-logistics information system in the medical industry; the study receives strong support from nurses for TAM in the use of that system.

Boyer and Olson (2020) concentrate on the characteristics of company culture on the part of the buying staff in their study on how businesses should accept internet purchasing to streamline this role on the upstream side of a supply chain. On the other hand, Richey et al. (2018) are investigating the effects of the application of technology to assess the efficacy of retail companies' organisational practices. Also, they investigate the moderating impact of technical supply chain turbulence and technological breath on the adoption of technology by businesses in their analysis of expanding the TAM. The authors contend that the more volatile technology environments, the stronger the association between the characteristics of TAM (such as PU and PEU) and the intention of the company to use the technology; however, the weaker the relationship between the intention of the company and the implementation of a supply chain technology, the greater the technological breath.

\subsection{Resource-based View of the Firm (RBV)}

Resource-based view (RBV) seeks to shed light on the backgrounds and their effect on company differentiation strategies to understand how companies gain sustainable competitive advantages (Wernerfelt, 1984; Barney, 1991; Hoopes et al., 2003). The theory is based on the premise that these businesses are a springboard of value-inducing 
competencies, according to Wernerfelt (1984), a view that includes interpreting company competencies from a knowledge-based point of view (Prahalad and Hamel, 2020; Conner and Prahalad, 1996). It focuses on those hard-to-imitate corporate characteristics that maximise greater market efficiency and sustainable competitive advantage (Barney, 1991; Prahalad and Hamel, 2020). The resources of an organisation include those assets that make it easier to devise and use value-adding techniques, both tangible and intangible (Barney, 1991; Wernerfelt, 1984). It is the special, intangible resources, such as information, compared to tangible ones, which pay companies rich dividends by providing value to various other development factors and are therefore more likely to generate strategic advantage. Tools with such capabilities could include the embedded traditions, culture, implicit awareness, brand image, etc. of a company that provide an enduring competitive advantage (von Krogh and Roos, 1995; Prahalad and Hamel, 2020; Collis and Montgomery, 1995; Bogner et al., 2019).

\section{Discussion and Conclusion}

This study aims to examine the relationship between the knowledge management strategy and organizational performance in Libya transportation industry. For business chambers, business associations and for various other forms of networking when forming strategies, the findings relating to construct would add value such as through the constructive competition. Since Knowledge Management System has a positive influence towards the transportation industry' performance, it is recommended to be considered as a focus area in the design and review of the transport industry policies in Libya. The necessity to corporate, reciprocity expectation, stability requirements, legitimacy perception and efficiency were found to have a positive effect towards Knowledge Management system. The study will shed some light on to prevailing knowledge and narrow the gap. It is hoped that this study will enlighten researchers who wish to study on this area of the overall picture.

The study aims to determine the correlation between the knowledge management and the organizational performance. It was established that Knowledge Management Process has a positive influence towards the transportation industry' performance. Consideration should be given when designing and reviewing the transport industry policies by policy makers and by business decision makers. The intensity of Knowledge Management process was found through the research to have a minor negative influence. The model is simple enough to be easily understood by the stakeholders while the model has been empirical tested to be significant.

Knowledge Management System offers a viable means to overcome some of the challenges faced by the transportation industry. Research findings indicated that even competing transportation industry can effectively benefit through Knowledge Management System. Lack of performing in transportation industry sector will add to the pressure to the government with rising unemployment, spread of poverty, pressure on social security, even political instability due to widespread representation of the 
transport industry sector in a country. The findings will assist the owners and managers of the transportation.

The management and the organizational knowledge have to be integrated into the process and procedures of the organization for increased growth and performance. Most of Libya transportation industry systematic record keeping system on financial transactions. Study also provides the impact of government utilization and other influencing factors for the economic growth of the success of the government industry. Another direction from this research is to investigate other types of product and services using the government as a vision and growth strategy in resource base view. A lot of research is needed to study the most effective way in which to attract customers with the utilization of government.

\section{References}

Ahn, T., Seewon, R., \& Ingoo, H. (2004). The impact of the online and offline features on the user acceptance of internet shopping malls. Electronic Commerce Research and Applications, 3 (4), 405-420.

Al-Alawi, A. I., Al-Marzooqi, N. Y., and Mohammed, Y. F. (2007). Organizational Culture and Knowledge Sharing: Critical Success Factors. Journal of Knowledge Management, (11:2), pp. 22-42.

Al-Shammari, M. (2015). Implementing a knowledge-enabled CRM strategy in a large company: A case study from a developing country, in Murray, J. (Ed.), Case Studies in Knowledge Management, 249-278, Idea Group Publishing.

Azam, S. M. F., Mohd Shukri, S., \& Ab Yajid, M. S. (2020). The impact of dynamic factors on the successful implementation of SAP. International Journal of Psychosocial Rehabilitation, 24(7), 5366-5376. https://doi.org/10.37200/IJPR/V24I7/PR270497.

Azam, S. M. F. and Moha Asri A. (2015). Differential Roles between Owner and Manager in Financial Practice That Contributes to Business Success: An Analysis on Malaysian Small Business, Academic Journal of Interdisciplinary Studies, 4 (1 S2): 123134.

Azam, S. M. F., \& Yusoff, S. K. M. (2020). Investment and financing analysis of automotive industry of China. International Journal of Psychosocial Rehabilitation, 24(7), 4848-4857. https://doi.org/10.37200/IJPR/V24I7/PR270464.

Azam, S. M. F., Haque, A., Sarwar, A. and Anwar, N. (2014), Training Program Effectiveness of Service Initiators: Measuring Perception of Female Employees of Bank Using Logistic Approach, Asian Research Journal of Business Management, 1 (2): 98-108

Barney, J. B. (1991). Firm Resources and Sustained Competitive Advantage. Journal of Management, 17(1), 99-120. 
Bhatt, G. (2020). Knowledge management in organizations: examining the interaction between technologies, techniques, and people. Journal of Knowledge Management, $5(1), 68-75$.

Bogner, W. C., Thomas, H., \& McGee, J. (2019). Competence and Competitive Advantage toward a Dynamic Mode. British Academy of Management, 10, 275-290.

Boyer, K. K., Olson, J. R. (2020). Drivers of Internet Purchasing Success. Production and Operations Management, 11(4), 480-498.

Buonanno, G., Faverio, P., Pigni, F., Ravarini A., Sciuto D., \& Tagliavini, M. (2015). Factors affecting ERP system adoption. Journal of Enterprise Information Management, 18(4), 384- 392.

Chun, L., Tham, J. and Azam S. M. F. (2019). Corporate Competence Determining Factors in China Telecom Industry in Achieving Customer Satisfaction, European Journal of Management and Marketing Studies, 4 (3), pp.75-101

Collis, D. J., \& Montgomery, C. A. (1995). Competing on Resources: Strategy in the 2020s. Harvard Business Review, July-Aug, 118-128.

Conner, K. R., \& Prahalad, C. K. (1996). A resource-Based theory of the firm: knowledge versus opportunism. Organization Science. 7(5), 477-501.

Davis, F. D. (1989). Perceived usefulness, perceived ease of use and user acceptance of information technology. MIS Quarterly, 13(3), 319-339.

De Silva, A. D. A., Khatibi, A. and Azam, S. M. F. (2017). Do the Demographic Differences Manifest in Motivation to Learn Science and Impact on Science Performance? Evidence from Sri Lanka, International Journal of Science and Mathematics Education, 16(S1), 47-67.

Dewi, N, Azam, S. M. F. and Yusoff, S. K. M. (2019). Factors influencing the information quality of local government financial statement and financial accountability, Management Science Letters, 9 (9): 1373-1384.

Fishbein, M., \& Ajzen, I. (1975). Belief, Attitude, Intention, and Behavior: An Introduction to Theory and Research. MA: Addison-Wesley.

Gold, A. H., Malhotra, A., \& Segars, A. (2001). Knowledge management: An organizational capabilities perspective. Journal of Management Information Systems, 18(1), 185-214.

Gupta, A. K., \& Govindarajan, V. (2020). Knowledge management's social dimension: Lessons from Nucor Steel, Sloan Management Review, 42(1), 71-80.

Harrison, T., \& Waite, K. (2015). Critical factors affecting intermediary web site adoption: understanding how to extend e-participation. Journal of Business and Industrial Marketing, 120(4/5), 187-199.

Haur, C. H., Khatibi, A. and Azam, S. M. F. (2017). Antecedents of Consumers' Perception towards Online Advertising in Malaysia: The Structure Equation Modeling Approach, European Journal of Management and Marketing Studies, 2 (3): 15-30.

Holowetzki, A. (2020). The relationship between knowledge management and organizational culture: an examination of cultural factors that support the flow and management of knowledge within an organization', Applied Information 
Management, University of Oregon, Eugene, OR, available at: http://aim.uoregon.edu/research/pdfs/Holowetzki2020.pdf.

Hoopes, D. G., Madsen, T. I., \& Walker, G. (2003). Introduction to the Special Issue: Why is there a resource-based view? Toward a theory of competitive heterogeneity. Strategic Management Journal, 24(10), 889.

Huang, E. (2008). Use and gratification in e-consumers. Internet Research, 18(4), 405-426. Jarvenpaa, S. L., \& Staples, D. S. (2020). The use of collaborative electronic media for information sharing: an exploratory study of determinants. Strategic Information Systems, 9, 129-154.

Katukurunda, K. G. W. K., Yajid, S. M. A, Khatibi, A. and Azam, S. M. F. (2019). Students' Satisfaction towards Biosystems Technology; Does Programme Quality Matters? (Evidence from Sri Lankan Perspectives), European Journal of Open Education and Elearning Studies, 3 (2): 174-190.

Kuruwitaarachchi, N., Yajid, S. M. A, Khatibi, A. and Azam, S. M. F. (2019). Enhance the use of Internet Based Advanced Communication Technologies in Small and Medium Scale Enterprises in Sri Lanka, European Journal of Social Sciences Studies, 3 (2): 44-57.

Lai, C. F. A., \& Pires, G. (2017). Testing of a model evaluating e-Government portal acceptance and satisfaction. The Electronic Journal Information Systems Evaluation,13(1), 35-46.

Lee, H. \& Choi, B. (2003). Knowledge management enablers, processes, and organisational performance: an integrative view and empirical examination. Journal of Management Information Systems, 20(1), 179-228.

Lewin, K. (1951) Field theory in social science; selected theoretical papers. D. Cartwright (ed.). New York: Harper \& Row.

Lin, H. F. (2016). Impact of organisational support on organisational intention to facilitate knowledge sharing. Knowledge Management Research and Practice, 4(1), 26-35.

Lopez, S. P., Peon, J. M. M., \& Ordas, C. J. V. (2004). Managing knowledge: the link between culture and organizational learning. Journal of Knowledge Management, 8(6), 93-104.

Maghfuriyah, A., Azam, S. M. F. and Shukri, S. (2019). Market Structure and Islamic Banking Performance in Indonesia: An Error Correction Model, Management Science Letters, 9 (9): 1407-1418.

Malhotra, N. K. (2020). Marketing Research: An Applied Orientation. 5th ed., Upper Saddle River, NJ: Prentice-Hall.

Mason, D., \& Pauleen, D. J. (2003). Perceptions of knowledge management: A qualitative analysis. Journal of Knowledge Management, 7(4), 38-48.

Murray, P., \& Donegan, K. (2003). Empirical linkages between firm competencies and organizational learning. The Learning Organization, 10(1), 51-62.

Nguyen, H. N., Tham, J, Khatibi, A. and Azam, S. M. F. (2019). Enhancing the Capacity of Tax Authorities and its Impact on Transfer Pricing Activities of FDI Enterprises 
in Ha Noi, Ho Chi Minh, Dong Nai, and Binh Duong Province of Vietnam, Management Science Letters, 9 (8): 1299-1310

Nonaka, I., \& Takeuchi, H. (1995). The Knowledge-Creating Company. Oxford: Oxford University Press.

Obaisat, H. (2015). Organizational Culture Impact of Organizational Knowledge Exchange: Applied Study within the Context of Free Zones, Corporation Knowledge and Studies Corporation, Jordan.

Pambreni, Y., Khatibi, A., Azam, S. M. F. and Tham, J. (2019). The Influence of Total Quality Management toward Organization Performance, Management Science Letters, 9 (9): 1397-1406.

Polanyi, M. (1966). The Tacit Dimension. London: Routledge \& Kegan Paul.

Politis, J. D. (2003). The connection between trust and knowledge management: what are its implications for team performance? Journal of Knowledge Management, 7 (5), 5566.

Prahalad, C. K., and Hamel, G. (2020). The Core Competence of the Corporation. Harvard Business Review, 68(3), 79-91.

Rachmawati, D., Shukri, S., Azam, S. M. F. and Khatibi, A. (2019). Factors Influencing Customers' Purchase Decision of Residential Property in Selangor, Malaysia, Management Science Letters, 9 (9): 1341-1348.

Richey, R. G., Tokman, M., \& Skinner, L. R. (2018). Exploring technological readiness in retail-supplier partnerships: how technology utilization can impact retailer performance. Journal of Business Research, 61(8), 842-849.

Robbins, S. P. (2018). Organisational Behaviour: Concepts, Controversies, Applications, (11th Ed.). New Jersey: Prentice Hall.

Simonin, B. L. (1997). The importance of collaborative know-how: An empirical test of the learning organisation. Academy of Management Journal, 40(5), 1150-1174.

Sinkula, J. M. (1994). Market information processing and organizational learning. Journal of Marketing, 58, 46-55.

Sundarraj, R. P., \& Wu, J. (2015). Using information-systems constructs to study onlineand telephone-banking technologies. Electronic Commerce Research and Applications, $4(4), 427-443$.

Takeuchi, H., \& Nonaka, I. (2004), Hitotsubashi on Knowledge Management. Singapore: John Wiley.

Tham, J., Yazid, M. S. A, Khatibi, A. A. and Azam, S. M. F. (2017). Internet and Data Security - Understanding Customer Perception on Trusting Virtual Banking Security in Malaysia, European Journal of Social Sciences Studies, 2 (7): 186-207

Tiwana, A. (2020). The Knowledge Management Toolkit - Practical Techniques for Building a Knowledge Management System. New Jersey: Prentice Hall.

Tracey, J. B., Tannenbaum, S. I., \& Kavanagh, M. J. (1995). Applying trained skills on the job: The importance of the work environment. Journal of Applied Psychology, 30(2), 239-252. 
Tsai, M. T., \& Lee, K. W. (2016). A study of knowledge internalization: from the perspective of learning cycle theory. Journal of Knowledge Management, 10(3), 57-71.

Tung, (2008). An extension of trust and TAM model with IDT in the adoption of the electronic logistics information system in HIS in the medical industry. International Journal of Medical Informatics,77(5), 324-335.

Turban, E., \& Aronson, J. E. (2001). Decision Support Systems and Intelligent Systems, 6th Ed., New Jersey: Prentice Hall.

Udriyah, U., Tham, J. and Azam, S. M. F. (2019). The Effects of Market Orientation and Innovation on Competitive Advantage and Business Performance of Textile SMEs, Management Science Letters, 9 (9): 1419-1428.

van Zolingen, S. J., Streumer, J. N., \& Stooker, M. (2001). Problems in knowledge management: A case study of a knowledge-intensive company. International Journal of Training and Development, 5(3), 168-184.

von Krogh, G., \& Roos, J. (1995). A Perspective on Knowledge, Competence and Strategy. Personnel Review, 24(3), 56-76.

Walczak, S. (2015). Organizational Knowledge Management System. The Learning Organization, 12(4), 330-339.

Wang, Y. S., Lin, H. H., \& Pin, L. (2016). Predicting consumer intention to use mobile service. Information Systems Journal, 16(2), 157-179.

Wernerfelt, B. (1984). A Resource-Based View of the Firm. Strategic Management Journal, 5, 171-180.

Yang, Z. Z., Tham, J. and Azam S. M. F. (2019). Negative Psychological Factors and Online Shopping Behaviour: A Review Among College Students' at Tongren City in China, European Journal of Management and Marketing Studies, 4 (4), pp.40-58.

Zack, M., McKeen, J., \& Singh, S. (2019). Knowledge management and organizational performance: an exploratory analysis. Journal of Knowledge Management, 13(6), 392409. 
Ahmad Mohamad Omar Omran, S. M. Ferdous Azam applied to their work. Under the terms of this license, no permission is required from the author(s) or publisher for members of the community to copy, distribute, transmit or adapt the article content, providing a proper, prominent and unambiguous attribution to the authors in a manner that makes clear that the materials are being reused under permission of a Creative Commons License. Views, opinions and conclusions expressed in this research article are views, opinions and conclusions of the author(s).Open Access Publishing Group and European Journal of Economic and Financial Research shall not be responsible or answerable for any loss, damage or liability caused in relation to/arising out of conflict of interests, copyright violations and inappropriate or inaccurate use of any kind content related or integrated on the research work. All the published works are meeting the Open Access Publishing requirements and can be freely accessed, shared, modified, distributed and used in educational, commercial and non-commercial purposes under a Creative Commons Attribution 4.0 International License (CC BY 4.0). 